\title{
Evaluation and comparison of bond strength of acrylic denture teeth to conventional heat cure and hypoallergenic denture base resin - an in-vitro study
}

\author{
Authors \\ Dr Manish Airan*1, Dr Shweta Airan², Dr Lekha Sharma ${ }^{3}$, Dr Rudraprasad IV ${ }^{4}$, \\ Dr Nandeeshwar DB $^{5}$ \\ ${ }^{1}$ MDS Prosthodontics, Private Practitioner, Smile Axis Dental Clinic, Rohtak \\ Email:drmanish.airan@gmail.com \\ ${ }^{2}$ MDS Orthodontics, Private Practitioner, Smile Axis Dental Clinic, Rohtak, \\ Ex-Resident PGIMS, Rohtak \\ Email: airanshweta@gmail.com \\ ${ }^{3}$ MDS Oral and Maxillofacial Surgery, Private Practitioner, Smile Axis Dental Clinic, Rohtak \\ ${ }^{4}$ Professor, Dept. of Prosthodontics, Bapuji Dental College and Hospital Davangere \\ ${ }^{5}$ Professor \& Head, Dept. Of Prosthodontics, Bapuji Dental College and Hospital, Davangere \\ Corresponding Author

\section{Dr Manish Airan} \\ Smile Axis Multispeciality Dental Clinic, 1290/29, Berimed house, Model Town, Rohtak (124001)
}

Ph - 7056795050, Email: drmanish.airan@gmail.com

\begin{abstract}
Background \& Objectives: Biocompatibility and bond to acrylic teeth constitute major requirement in choosing ideal denture base material. Hence, this in vitro study was intended to evaluate and compare bond strength of acrylic denture teeth to conventional heat cure and hypoallergenic denture base resin i.e. Group 1: Acrylic denture teeth bonded to conventional denture base resin (Trevalon). Group 2: Acrylic denture teeth bonded to hypoallergenic denture base resin (Sinomer $®)$.

Method: A custom-made mould of brass was made to make wax cylinders of $6 \mathrm{~mm} X 6 \mathrm{~mm}$ dimensions. Molars from acrylic teeth mould (Premadent) were selected and there ridge lap surface were flattened with an acrylic trimmer and polished. Cleaned denture teeth surfaces were attached to wax patterns and were invested with Type III dental stone into Kavo metal flask and dewaxed. For GROUP 1 (Control) dewaxed Kavo metal flask was packed with conventional heat cure denture base resin in dough stage. For GROUP 2 (Experimental) dewaxed Kavo metal flask were packed with hypoallergenic denture base resin. Each one of the tested materials was cured according to the manufacturer's instructions. After curing, specimens were retrieved and finished and polished.

To measure bond strength, each specimen was embedded in autopolymerizing resin to transfer it to mounting jig of Universal Testing Machine. After embedding, the specimen was stored in water at room temperature for 4 weeks before testing and all specimens were tested on the same day at room temperature. The acrylic resin blocks were held on mounting jig and force was applied parallel to the bonding surface at tooth-base interface. Amount of force at fracture will be recorded in Newton (N) and maximum stress will be recorded in Mega Pascals.

Results: The data obtained from the study were tabulated and subjected to statistical analysis using Unpaired 't' test
\end{abstract}


to compare flexural strength between control and experimental groups.

Intergroup comparisons yielded a significant difference of mean bond strength between group $1(21.20 \pm 1.21)$ and group 2 (15.05 \pm 0.73$)$. This suggested, the greater bond strengths for heat polymerized specimens. In all groups most of the failures were of the adhesive type.

Interpretation \& Conclusion: Within the limitations of the study, it was concluded that overall, significantly higher shear bond strength to the denture teeth tested were obtained with conventional heat polymerized denture base resin rather than hypoallergenic Alldent Sinomer ${ }^{\circledR}$ denture base resin and in all groups most of the failures were of the adhesive type. Mechanical retentive aids are required for hypoallergenic Alldent Sinomer ${ }^{\circledR}$ denture base resin for stronger bonding with denture teeth as instructed by manufacturer.

Keywords: Denture Base material, Hypoallergenic denture base resin, tooth bond strength, Sinomer.

\section{Introduction}

Essential requirements for denture base polymers are adequate mechanical properties, sufficient aesthetics, biocompatibility, easy handling of resin and minimal release of residual compounds such as residual monomers. ${ }^{1}$ Various materials and fabrication techniques have been used to fabricate dentures. The material which has stood the test of time as denture base resin is PMMA.

Prefabricated acrylic resin teeth are the most popular artificial materials for denture teeth. Apart from having an advantage of economy and chemical bonding to denture base, it also shows life like translucency in thin sections. However, fracture and debonding of acrylic teeth from the denture base is the most common clinical problem. $^{2}$ Also, the number of patients with allergies is increasing and as, a consequence, dentists are confronted with more patients reporting allergic reactions to polymethyl methacrylate denture base materials. ${ }^{3}$

Apart from patients, compounds of denture base resin prior to polymerization can cause hypersensitization and allergy to the dentists and dental laboratory personnel. ${ }^{1}$ Therefore, the use of a hypoallergenic denture base material for patients susceptible to allergic reactions and requiring a removable prosthesis is desirable for dental personnel as well. $^{2}$

Another frequently encountered problem is of recurrent denture fractures, which also remains an unresolved problem causing inconvenience for denture wearers. Among these fractures, a survey report concluded that commonest type of fracture is debonding or fracture of denture teeth in both complete and partial dentures. ${ }^{4}$

Therefore, to overcome these shortcomings of PMMA denture base resin, a material is required which is not only hypoallergenic but also bonds well to denture acrylic teeth. However to overcome former problem modified methacrylate based denture base resins like Sinomer (heat polymerized) are available which exhibits lower residual monomer content than heat polymerized PMMA material. ${ }^{8}$ But there were no reports claiming the efficient bonding of such material to acrylic denture teeth.

Hence, the aim of this in vitro study is to evaluate the bond strength of acrylic denture teeth to hypoallergenic denture base resin.

\section{Materials and Methods}

A commonly used brand of denture teeth (Premadent, Ashvin, New Delhi, India) was chosen for bonding with two types of heat cured denture base resin: Conventional Heat Cure Resin (Trevalon, Dental Products of India Pvt. Ltd., Mumbai, India) and Hypoallergenic denture base resin (Sinomer ${ }^{\circledR}, \quad$ Alldent, Ruggell, Liechtenstein). The denture base resins used in the study are listed in Table 1, with polymerization method followed in the study. Thirty specimens were prepared for each type of denture base resin. Each of the specimens consisted of a ridge lap surface of tooth joined to a cylindrical conventional / hypoallergenic denture base resin. The ridge lap surface of each tooth was flattened with an acrylic trimmer at a speed of 1000rpm. Bonding surface was finished with 400 grit sandpaper. All acrylic teeth were thoroughly 
washed with hot detergent solution, followed by flushing with clean hot water for 2 minutes. This ensured removal of surface debris, wax, oil and secretions of skin that might have accumulated during storage and transport of teeth.

A master brass metal mould (Fig. 1) was used to make wax cylinders of $6 \times 6 \mathrm{~mm}$ dimensions. Modelling wax was melted in a wax melting jar and was poured in the mould and allowed to solidify, and then it was removed from the mould and tooth was attached each wax cylinder by softening one end of pattern without disturbing the margins of the wax cylinder. Sixty specimens were fabricated in a similar manner.

Teeth attached to wax cylinder/specimen were divided in two groups of 30 specimens each and were than invested with a Type III dental stone in a two different conventional metal flask. Wax was boiled out with freshly boiled water and left to bench cool to room temperature. Cold mold seal was then applied to the mold space. After drying of cold mold seal, flasks were packed with denture base resins and processed as mentioned in Table 1.

\section{Table 1}

\begin{tabular}{|c|c|c|}
\hline & $\begin{array}{ll}\text { Denture } & \text { Base } \\
\text { Resin } & \\
\end{array}$ & Polymerisation Method \\
\hline Group 1 & $\begin{array}{l}\text { Trevalon, } \\
\text { Dental } \\
\text { Products of } \\
\text { India Pvt. Ltd., } \\
\text { Mumbai, India }\end{array}$ & $\begin{array}{l}\text { After packing in dough stage, } \\
\text { under } 3000 \text { psi pressure in a } \\
\text { hydraulic press flask was } \\
\text { clamped and was allowed to } \\
\text { bench cure for } 30 \text { minutes. } \\
\text { After bench curing the flasks } \\
\text { were placed in an acrylizer for } \\
\text { processing for } 9 \text { hours at } \\
165^{\circ} \mathrm{F}\end{array}$ \\
\hline Group 2 & $\begin{array}{l}\text { Sinomer®, } \\
\text { Novodent, } \\
\text { Germany }\end{array}$ & $\begin{array}{l}\text { According to the } \\
\text { manufacturer's instructions, } \\
\text { flask was packed with Alldent } \\
\text { Sinomer® heat cured resin } \\
\text { paste directly from box and } \\
\text { packed flasks were placed } \\
\text { directly into the water at } \\
158^{\circ} \mathrm{F} 176^{\circ} \mathrm{F} \text { for } 20 \text { minutes } \\
\text { and then will be boiled in } \\
\text { water at } 203^{\circ} \mathrm{F} \text { for another } 20 \\
\text { minutes. }\end{array}$ \\
\hline
\end{tabular}

After the bench cooling for $2 \frac{1}{2} 2$ hours procedure ${ }^{9}$, the flasks were opened and the specimens were carefully retrieved. The excess flash was trimmed using laboratory micromotor (AC motor) and polished. Each specimen was marked by a sample number and divided into Group 1 and Group 2, according to denture base resin used (Table 2). All specimens were stored in water at room temperature for 4 weeks until testing.

For testing each tooth was embedded in autopolymerising acrylic resin (Fig. 2) to transfer it to the mounting jig of the universal testing machine. Shear bond strength was tested on a universal testing machine (Hounsfield Test Equipment Ltd.) using a $500 \mathrm{Kg}$ load cell with a cross head speed of $0.5 \mathrm{~mm} / \mathrm{min}$ (Fig. 3). Fractured surfaces were examined and classified as adhesive or cohesive type of failure.

Data collected by experiments were computerized and analysed using the Statistical Package for the Social Sciences (SPSS version 14.0). Since the data were of the continuous type, parametric tests were used for analysis. Mean and Standard Deviation (SD) were calculated. Unpaired' $t$ ' test was used to compare flexural strength between control and experimental groups. P-value <0.05 was considered statistically significant.

Table -2 Teeth and Material used for the study

\begin{tabular}{|c|c|c|c|}
\hline Group & No. of & Type of teeth & Material \\
\hline 1 & 30 & Premadent & $\begin{array}{c}\text { Trevalon Conventional } \\
\text { Heat Cure } \\
\text { resin }\end{array}$ \\
\hline 2 & 30 & Premadent & $\begin{array}{c}\text { Sinomer }{ }^{\circledR} \text { Hypoallergenic } \\
\text { Heat Cure Resin }\end{array}$ \\
\hline
\end{tabular}

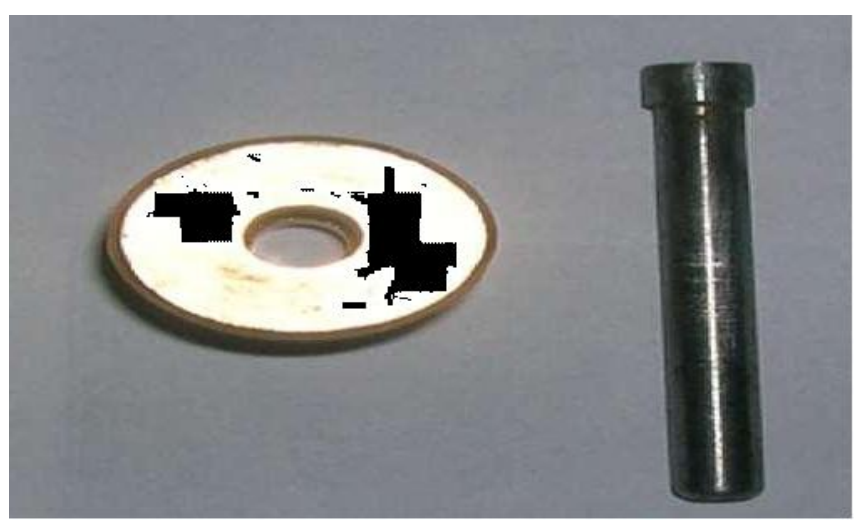

Fig. 1 - Brass Mould 


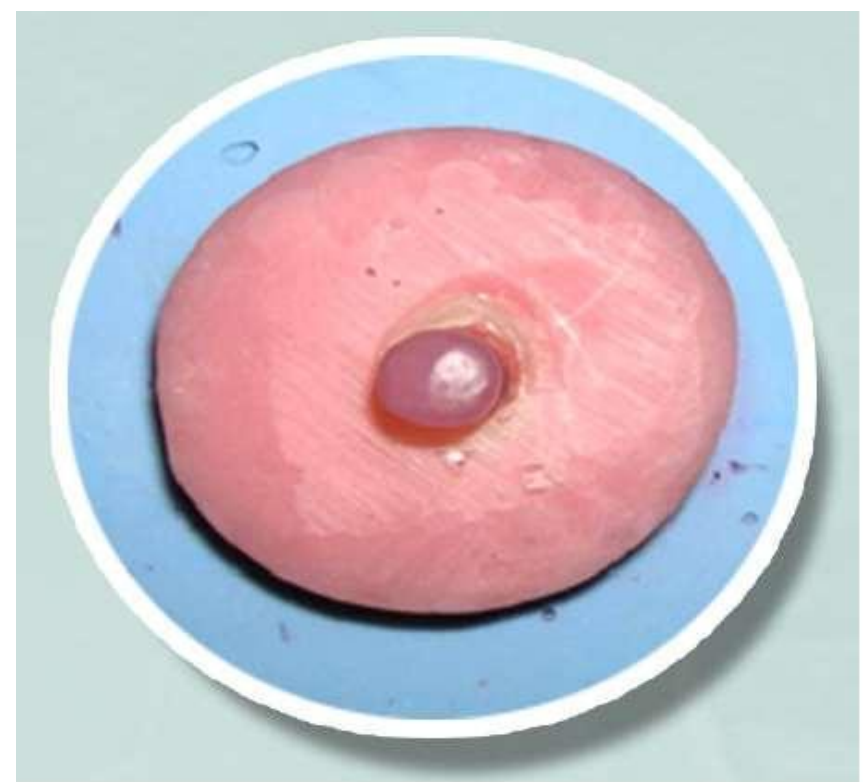

Fig. 2 Test Specimens embedded In Autopolymerising Resin

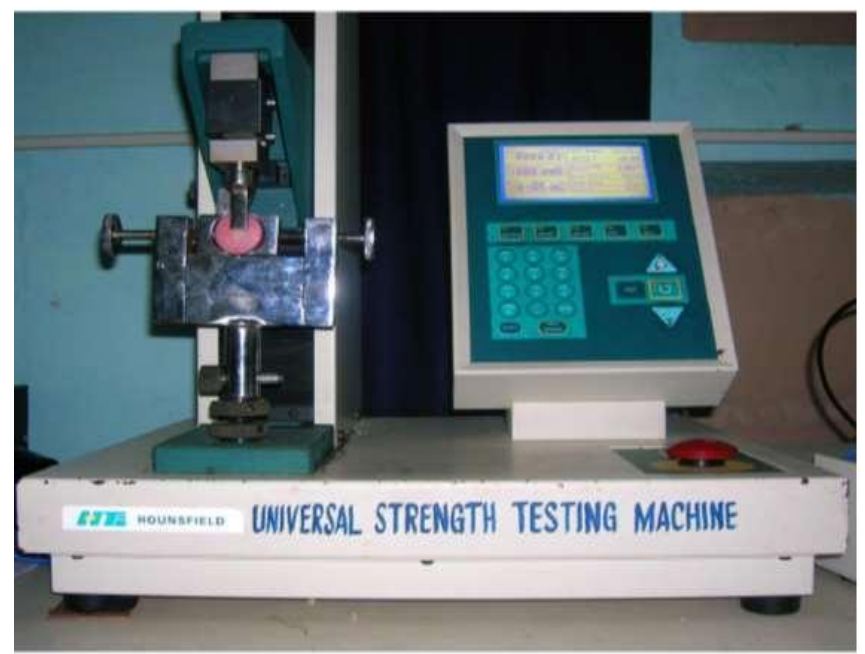

Fig. 3 Test Specimens Embedded In Autopolymerising Resin

\section{Results}

Mean shear bond strength, standard deviation, maximum and minimum values, range of shear bond strength are illustrated in Table 3 . $\mathrm{T}$ value and $\mathrm{p}$ value for load and shear bond strength are illustrated in Table 4 and Table 5 respectively.

Group 1, Premadent teeth bonded to conventional heat cured denture base resin had the highest shear bond strength with a mean value of 21.20 and standard deviation of 1.21.

Group 2, Premadent teeth bonded to hypoallergenic Alldent Sinomer resin had mean shear bond strength of 15.05 with standard deviation of 0.73 .

Multiple group comparison showed a statistically significant difference between groups 1 and 2 $(\mathrm{P}<0.001)$.

Intergroup comparisons yielded a significant difference of mean bond strength between group 1 $(21.20 \pm 1.21)$ and group $2(15.05 \pm 0.73)$. This suggested the greater bond strengths for conventional denture base resin specimens. (Graph 1 and Graph 2)

In all groups most of the failures were of the adhesive type except for four specimens in group 1 and three specimen in group 2, which had both adhesive and cohesive (within resin) failure.

\section{Calculations for Conversion of $\mathrm{Kg}$ into $\mathrm{N} / \mathrm{mm}^{2}$}

$$
\mathrm{N} / \mathrm{mm}^{2}=\frac{\mathrm{W}(\mathrm{Kg}) \times 9.81}{\left(\frac{\pi}{4}\right) \times \mathrm{D}^{2}}
$$

$\mathrm{W}=$ Fracture load

$\mathrm{D}=$ Diameter of cylinder $(6 \mathrm{~mm})$

Table -3 Mean and Standard Deviation of Various Groups

\begin{tabular}{|c|c|c|c|c|c|}
\hline Group & Mean & SD & Maximum & Minimum & Range \\
\hline 1 & 21.20 & 1.21 & 23.76 & 19.28 & 4.48 \\
\hline 2 & 15.05 & 0.73 & 16.58 & 14.03 & 2.55 \\
\hline
\end{tabular}

Table - 4

\begin{tabular}{|c|c|c|c|}
\hline Group & Mean \pm SD & t value & $\mathrm{p}$ value \\
\hline 1 & $60.5829 \pm 3.46$ & \multirow{2}{*}{23.01} & $<0.0001 * *$ \\
\hline 2 & $43.005 \pm 2.08$ & & \\
\hline
\end{tabular}

Table - 5

\begin{tabular}{|c|c|c|c|}
\hline Group & Mean \pm SD & t value & $\mathrm{p}$ value \\
\hline 1 & $21.20 \pm 1.21$ & \multirow{2}{*}{23.08} & $<0.0001^{* *}$ \\
\hline 2 & $15.05 \pm 0.73$ & & \\
\hline
\end{tabular}

Significant difference was found between: 1 and 2 $(\mathrm{P}<0.0001)$. 
$\underline{\text { Graph } 1}$
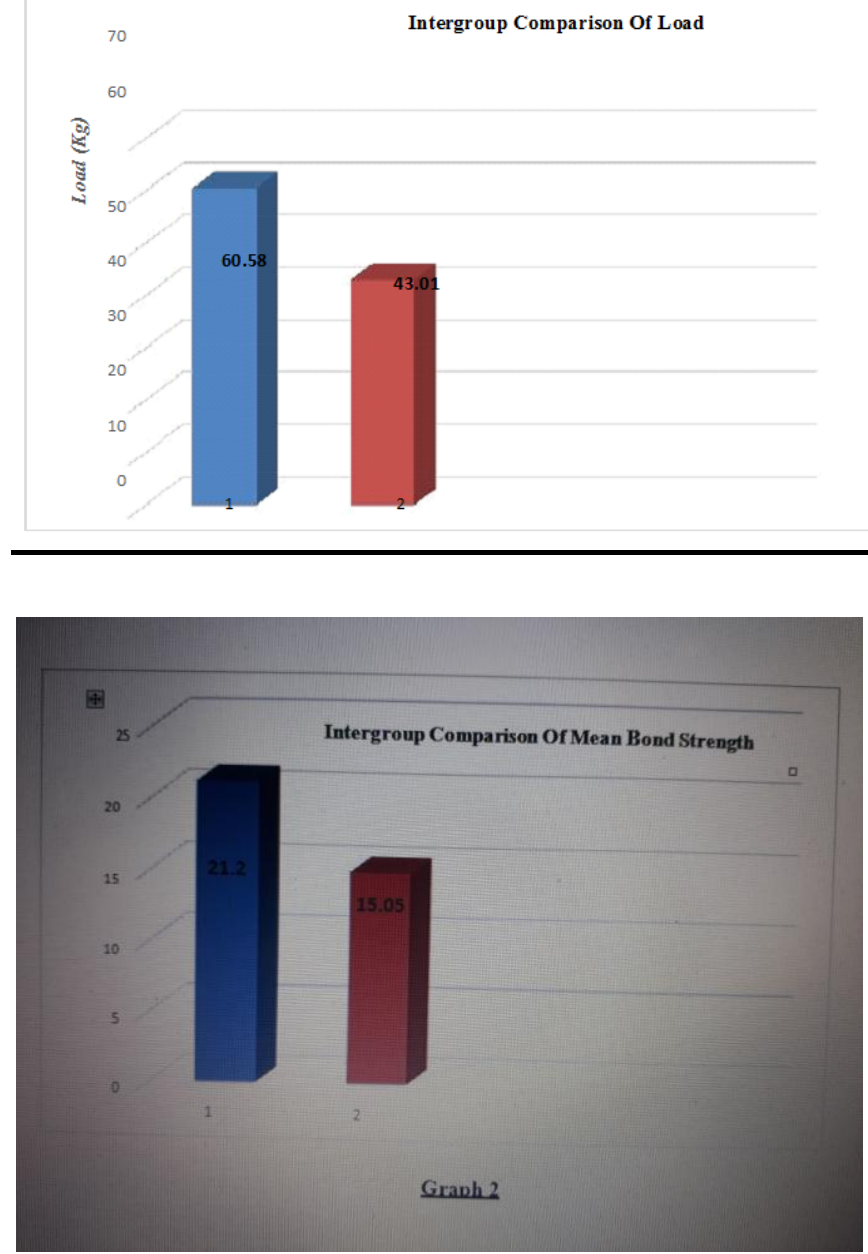

\section{Discussion}

Partial or complete dentures are more commonly constructed for the elderly group of population. Teeth debonding from dentures can be frustrating to patients as well as the dentist. Research has been carried out and is continuing to study the issue of bonding acrylic teeth to denture base resin.

Selection of more compatible combinations of denture base resins and acrylic teeth may reduce the number of prosthesis fracture and resultant repairs. ${ }^{9}$

Various materials and fabrication techniques have been used to prepare dentures. An acrylic resin denture base material has been available to the dental profession for over 60 years. Although materials with superior properties have been available in the market for some time, it still remains the most popular choice. ${ }^{7}$
Being the most popular choice, the problems associated PMMA are also very common. Allergic reactions and local chemical irritation caused by PMMA have been reported. The most frequent complaint of patients is a burning sensation in the mouth, primarily in the palatal mucosa that is in direct contact with maxillary dentures but also in the tongue, oral mucosa, and oropharynx. The main clinical signs are redness, swelling and pain in the oral mucosa, vesicles and ulcerations, and labial oedema. ${ }^{10}$

Such adverse reactions caused by denture base polymers have been attributed to substances leaching from these materials, especially unreacted residual monomers. This leaching results from the process of diffusion. As the water penetrates the matrix and expands the opening between polymer chains, unreacted and leachable monomers may diffuse out. Substances leaching from dentures into saliva are conveyed to the oral mucosa and may cause adverse reactions. ${ }^{10}$

As of teeth, Acrylic resin teeth are often preferred over porcelain teeth because they chemically bond to denture base material and are easy to adjust in a close inter ridge space. ${ }^{11,12}$

The majority of preformed artificial teeth are made up of acrylic or vinyl acrylic resins. Poly (methylmethacrylate) resins used in the fabrication of prosthetic teeth are very similar to those used in denture base construction. Nevertheless, the degree of cross linking within the prosthetic teeth is somewhat greater than that within polymerized denture bases. This increase is achieved by elevating the amount of cross linking agent in denture base liquid. The resultant displays polymer display enhanced stability and improved clinical properties. Cervical portions of prosthetic teeth often exhibit reduced crosslinking. This feature facilitates chemical bonding with denture base resin. ${ }^{12}$

However, debonding of acrylic teeth from denture base remains a major problem in prosthodontic practice. It has been estimated that between $22 \%$ and $30 \%$ of denture repairs involve tooth 
debonding, usually in anterior region of denture. This detachment may be attributed to:

1) Lesser ridge lap surface area available for bonding.

2) Direction of stress encountered during function.

3) Incompatible surface conditions at tooth base interface

- Contamination of joining surfaces.

- Difference in the structure of two components because of their different processing roster.

4) Processing errors

- Polymerizing denture base resin must come in physical contact with the denture tooth resin.

- Polymerization network of denture base resin must react with acrylic tooth polymer to form an interwoven polymer network.

5) Careless application of separating medium during processing.

6) Insufficient available monomer during processing. 9

7) Method of denture base resin polymerization i.e. conventional heat cure polymerization or microwave polymerization. $^{7}$

8) The co-polymerization (cross-linking) of the tooth resin. ${ }^{13,14}$

Taking into account the significance of the problem of bond failure and allergic reaction to conventional heat cure denture base resin, the present study was conducted to evaluate and compare the shear bond strength between conventionally denture base resin and hypoallergenic denture base resin..

The specimens were divided into two groups (i.e. Group 1 \& 2), 30 specimens were studied in each group.

The hypoallergenic material used in the study is Alldent Sinomer ${ }^{\circledR}$ manufactured by Novodent, Germany and has been claimed to be hypoallergenic. It is a one component denture base and relining material (paste), free of methylmethacrylate monomer and without benzoylperoxide. It contains polymethylmethacrylate (PMMA, with residual monomer) and high acrylate monomer. This denture base material is, according to present knowledge, toxicologically harmless. The possibility of it causing an allergy is extremely remote.

Group 1 was studied to evaluate the shear bond strength between Premadent molars bonded to conventional heat cured acrylic denture base resin. Group 2 studied to evaluate the shear bond strength between Premadent molars bonded to the hypoallergenic (Sinomer®) heat cure acrylic denture base resin.

It was observed that the mean shear bond strength of conventional heat cured specimens was more than Sinomer® specimens. Conventional denture base specimens exhibited a statistically significant $(\mathrm{p}<.001)$ higher mean bond strength than hypoallergenic denture base specimen. This inferior bond strength was probably because of lack of monomer and hence penetration of same into tooth and acrylic resin polymer networks. The bond strength depends on the degree of penetration of monomer and the strength of interwoven polymer network formed thereafter.

Another reason for inferior bond strength in hypoallergenic denture base resin could be the presence of high acrylate compound and higher amount of pre polymerized PMMA in the paste, as the degree of cross linking in resin or in acrylic teeth increases bonding between them decreases. Although manufacturers claim that this material bonds well with the acrylic denture teeth but they also recommend the use of mechanical retention aids for improved retention.

Commercially, a vast number of teeth and denture base resins are available for denture construction. However, there is usually little or no mention of bond strength or compatibility of acrylic teeth to denture base resin by the manufacturers. The selection of more compatible combinations of acrylic teeth and denture base resin with proper 
handling and processing of materials along with use of mechanical and chemical retentive aids will not only reduce the number of prostheses failures and their resultant repairs. But also make the denture more acceptable to the wearer and reduce the chance of adverse hypersensitive reactions

It must be noted that in vitro studies are limited in predicting the success of a material or technique in clinical use. The use of a simple cylindrical shaped specimens rather than a complex denture design, as well as the absence of longer periods of water storage were the limitations of the present study. Moreover only one brand of conventional acrylic resin, hypoallergenic denture base and denture teeth were tested in this study.

Within the limitations of this study, the material of concern Sinomer® may be able to solve the problem of allergic reaction (as claimed by manufacturers) but its bonding with acrylic denture teeth needs to be improved or proper mechanical and chemical aids should be used to improve its bond strength. Hence, further research is needed in this direction.

\section{Conclusion}

Within the limitations of the study, the following conclusions were drawn:

1) Overall, significantly higher shear bond strength to the denture teeth tested were obtained with conventional heat polymerized denture base resin rather than hypoallergenic Alldent Sinomer® denture base resin.

2) In all groups most of the failures were of the adhesive type.

3) Mechanical retentive aids are required for hypoallergenic Alldent Sinomer ${ }^{\circledR}$ denture base resin for stronger bonding with denture teeth as instructed by manufacturer.

\section{Funding: None}

Conflict of Interest: None

Ethical approval: Not required

\section{References}

1. Lassila LVJ, Vallittu PK. Denture base polymer Alldent Sinomer®: mechanical properties, water sorption and release of residual compounds. J Oral Rehabil 2001;28:607-13.

2. Thean HPY, Chew CL, Goh KI. Shear bond strength of denture teeth to base: A comparative study. Quintessence Int 1996; 27 (6): 425-428.

3. Pfeiffer P, An A, Schmage P. Repair strength of hypoallergenic denture base materials. J Prosthet Dent 2008;100:292301.

4. Darbar UR, Huggett R, Harrison A. Denture fracture - a survey. Br Dent $\mathrm{J}$ 1994;176:342-5.

5. Kawara M, Carter JM, Ogle RE and Johnson RR. Bonding of plastic teeth to denture base resins. J Prosthet Dent 1991; 66 (4): 566-71.

6. Cunningham JL and Benington LC. Bond strength variation of synthetic resin teeth in denture. Int J Prosthedont 1995; 8 (1): 69-72.

7. Barbosa DB, Barao VAR, Monteiro DR, Compagnoni MA and Marra J. Bond strength of denture teeth to acrylic resin: Effect of thermocycling and polymerization methods. Gerodontology 2008. (Accepted for publication).

8. feiffer P, Rolleke C, Sherif L. Flexural strength and moduli of hypoallergenic denture base materials. J Prosthet Dent 2005;93:372-7.

9. Patil SB, Naveen BH and Patil NP. Bonding acrylic teeth to acrylic resin denture bases: A review Gerodontology 2006; 23: 131-139.

10. Chaves CAL, Machado AL, Vergani CE, Souza RF, Giampaolo ET. Cytotoxicity of denture base and hard chairside reline materials: A systematic review. J Prosthet Dent 2012;107:114-127. 
11. Schneider RL, Curtis ER and Clancy JMS. Tensile bond strength of acrylic resin denture teeth to microwave or heat processed denture base. J Prosthet Dent 2002; 88:145-150.

12. Anusavice, Kenneth J., Phillips' Sciences of Dental materials. 11th edition.

13. Huggett R, Jagger RG and Bates JF. Strength of the Acrylic Denture Base Tooth Bond. Br. Dent J 1982; 153: 187190.

14. Clancy MSJ and Boyer DB. Comparative bond strengths of light-cured, heat-cured and autopolymerizing denture resins to denture teeth. J Prosth Dent 1989; 61 (4): 457-462. 